\title{
PENGARUH STRATEGI PEMBELAJARAN TEAM TEACHING DAN MOTIVASI BELAJAR SISWA TERHADAP HASIL BELAJAR MENGANALISIS RANGKAIAN LISTRIK
}

${ }^{1}$ Furi Endang Palupi, ${ }^{2}$ Soeprijanto, ${ }^{3}$ Faried Wadjdi

${ }^{1,2,3}$ Pendidikan Teknik ElektroTeknik Elektro, Universitas Negeri Jakarta

\begin{abstract}
This study aims to determine the effect of learning team teaching strategy and student learning motivation on the results of learning to analyze electrical circuits. This research was conducted at SMKN 1 Tambelang in February 2017. The sample of this research is students consisting of 2 classes of experimental class of students taught with team teaching amounted to 30 students and control class of students who were taught non-team teaching consisted of 30 Students so the total amounted to 66 students. Of the 66 students were given a questionnaire about student learning motivation, the results will be grouped into 2 ie students who have high motivation and students who have low motivation.

Normality data test using lilefors test obtained by each group data and normal distributed line. The result of homogeneity using bartlett test which result of the data is homogeneous. Hypothesis test with $F$ test of Anava $2 X 2$ with significant level 0,05 . From the test results obtained $F_{\text {count }}$ values between treatments $=49.824$ and $F_{\text {table }}=4,196$. It can be concluded that $F_{\text {count }}>F_{\text {table }}$, it can be concluded that overall there is a real difference between team teaching and non-team teaching learning strategy toward learning result of analyzing electrical circuit. The second hypothesis is tested further using dunnet test obtained $t_{\text {count }}=11.797$ and $t_{\text {table }}=1.70$. It can be concluded that $t_{\text {count }}>t_{\text {table }}$, it is concluded that the result of learning to analyze electrical circuits for students who follow teaching team teaching strategy and have higher motivation higher than students who follow non-team teaching strategies and have high motivation. Results of the third hypothesis obtained $t_{\text {count }}=$ 1.81 and $t_{\text {table }}=1.70$. It can be concluded that $t_{\text {count }}>t_{\text {table }}$, it is concluded that the result of learning to analyze electric circuits for students who follow teaching team teaching strategy and have lower motivation lower than students who follow non-team teaching strategy and have low motivation.
\end{abstract}

Keywords: Team Teaching, Learning Motivation, Analyzing Electric Circuit

\begin{abstract}
Abstrak
Penelitian ini bertujuan untuk mengetahui pengaruh strategi pembelajaran team teaching dan motivasi belajar siswa terhadap hasil belajar menganalisis rangkaian listrik. Penelitian ini dilakukan di SMKN 1 Tambelang pada bulan Februari 2017. Sampel dari penelitian ini adalah siswa yang terdiri dari 2 kelas yaitu kelas eksperimen dari siswa yang diajar dengan team teaching berjumlah 30 siswa dan kelas kontrol dari siswa yang diajar non-team teaching terdiri dari 30 siswa sehingga total berjumlah 60 siswa. Dari 60 siswa tersebut diberikan kuisioner tentang motivasi belajar siswa, hasilnya akan dikelompokkan menjadi 2 bagian yaitu siswa yang memiliki motivasi tinggi dan siswa yang memiliki motivasi rendah

Uji hipotesis dengan uji F Anava $2 X 2$ dengan taraf signifikan 0,05. Dari hasil pengujian diperoleh nilai $F_{\text {hitung }}$ antar perlakuan $=49,824$ dan $\mathrm{F}_{\text {tabel }}=4$ 4196. Dapat disimpulkan bahwa $\mathrm{F}_{\text {hitung }}>\mathrm{F}_{\text {tabel }}$, maka diperoleh kesimpulan bahwa secara keseluruhan terdapat perbedaan nyata antara strategi pembelajaran team teaching dan non - team teaching terhadap hasil belajar menganalisis rangkaian listrik. Hipotesis kedua dilakukan uji lanjut menggunakan uji dunnet diperoleh $t_{\text {hitung }}=11,797$ dan $t_{\text {tabel }}=1,70$. Dapat disimpulkan bahwa $t_{\text {hitung }}>t_{\text {tabel }}$ , maka diperoleh kesimpulan yaitu hasil belajar menganalisis rangkaian listrik bagi siswa yang mengikuti strategi pembelajaran team teaching dan memiliki motivasi tinggi lebih tinggi daripada siswa yang mengikuti strategi pembelajaran non-team teaching dan memiliki motivasi tinggi. Hasil hipotesis ketiga diperoleh thitung $=1,81$ dan $t_{\text {tabel }}=1,70$. Dapat disimpulkan bahwa $t_{\text {hitung }}>t_{\text {tabel }}$, maka diperoleh kesimpulan yaitu hasil belajar menganalisis rangkaian listrik bagi siswa yang mengikuti strategi pembelajaran team teaching dan memiliki motivasi rendah lebih rendah daripada siswa yang mengikuti strategi pembelajaran non - team teaching dan memiliki motivasi rendah.
\end{abstract}

Kata kunci Team Teaching, Motivasi Belajar, Menganalisis Rangkaian Listrik

\section{PENDAHULUAN}

Mata pelajaran menganalisis rangkaian listrik merupakan materi hitungan dan praktek. Pada umumnya siswa menganggap bahwa materi hitungan itu sulit, sehingga motivasi dan keaktifan belajar menjadi berkurang. Sedangkan pelaksanaan belajar secara praktek, siswa dibimbing untuk dapat terampil dan memahapi konsep dasar listrik.
Berdasarkan informasi, banyak siswa yang belum memahami konsep dasar untuk menganalisis rangkaian listrik, dilihat dari rendahnya hasil belajar siswa yang masih dibawah KKM. Hal tersebut dapat disebabkan karena daya serap siswa terhadap bahan yang diberikan ada yang cepat, ada yang sedang, dan ada yang lambat. Faktor intelegensinya yang mempengaruhi daya serap siswa terhadap bahan 
ajar yang diberikan, oleh karena itu diperlukan strategi pembelajaran yang tepat untuk melatih kemampuan tersebut.

Strategi Team Teaching merupakan strategi pembelajaran yang kegiatan proses pembelajarannya dilakukan oleh lebih dari satu orang guru dengan pembagian peran dan tanggung jawabnya masing-masing. Tim pengajar atau guru yang menyajikan bahan pelajaran dengan metode mengajar beregu ini, menyajikan bahan pengajaran yang berbeda dengan tujuan yang sama. Penelitian yang telah ada yang mendukung salah satunya adalah pengaruh penerapan strategi pemebelajaran team teaching terhadap hasil belajar siswa. Adapun peningkatan hasil belajar sebelum dan sesudah mendapatkan strategi pembelajaran team teaching yaitu sebesar $24,3 \%$. Penggunaan strategi pembelajaran team teaching memberikan pengaruh positif terhadap hasil belajar teori siswa (Sutopo, 2011: 7).

Dengan demikian, strategi pembelajaran Team Teaching diapakai untuk menjadi solusi dalam membangun kondisi kegiatan pembelajaran yang kondusif, dan menyenangkan, sedangkan motivasi belajar sebagai penyemangat dari dalam diri siswa untuk menjadi dorongan internal pribadi dalam melakukan aktivitas belajar secara giat agar memperoleh hasil belajar yang optimal.

Berdasarkan uraian diatas dalam hal ini peneliti merasa perlu melakukan penelitian mengenai pengaruh strategi pembelajaran team teaching dan motivasi belajar siswa terhadap hasil belajar mata pelajaran menganalisis rangkaian listrik.

\section{METODE}

Penelitian ini menggunakan metode eksperimen dengan rancangan $2 \times 2$. Variabel terikat dalam penelitian ini adalah hasil belajar menganalisis rangkaian listrik. Sebagai variabel bebas pertama adalah strategi pembelajaran, yang dibedakan menjadi dua kelompok, yaitu strategi pembelajaran team teaching sebagai kelompok eksperimen dan strategi pembelajaran non-team sebagai kelompok kontrol. Sebagai variabel bebas kedua adalah motivasi belajar, yang dibedakan menjadi dua kelompok yaitu motivasi belajar tinggi dan motivasi belajar rendah. Secara visual rancangan penelitian yang akan dilakukan adalah seperti pada tabel di bawah ini:

Tabel 1. Rancangan Penelitian

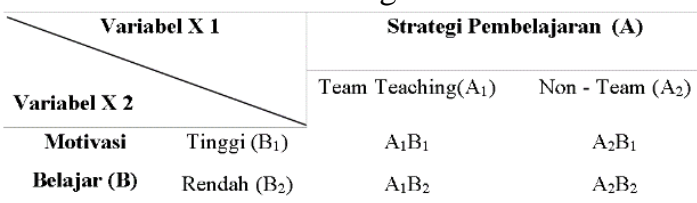

Populasi, Sampel dan Teknik Pengambilan Sampel

Populasi penelitian ini adalah seluruh siswa kelas X SMK Negeri 1 Tambelang program keahlian Teknik Otomasi Industri. Sampel penelitian ditentukan dengan Teknik sample random sampling kelas. Dengan mengambil kelas $\mathrm{X}$ yang berjumlah 12 kelas, yang kemudian di random hingga di dapat dua kelas yaitu satu kelas eksperimen dan satu kelas kontrol dengan jumlah siswa masing- masing kelas sebanyak 30 orang.

Semua siswa dari kedua kelompok belajar dibagikan instumen tes motivasi belajar untuk menentukan siswa mana yang memiliki motivasi belajar kelompok tinggi dan siswa yang memiliki motivasi belajar kelompok rendah.

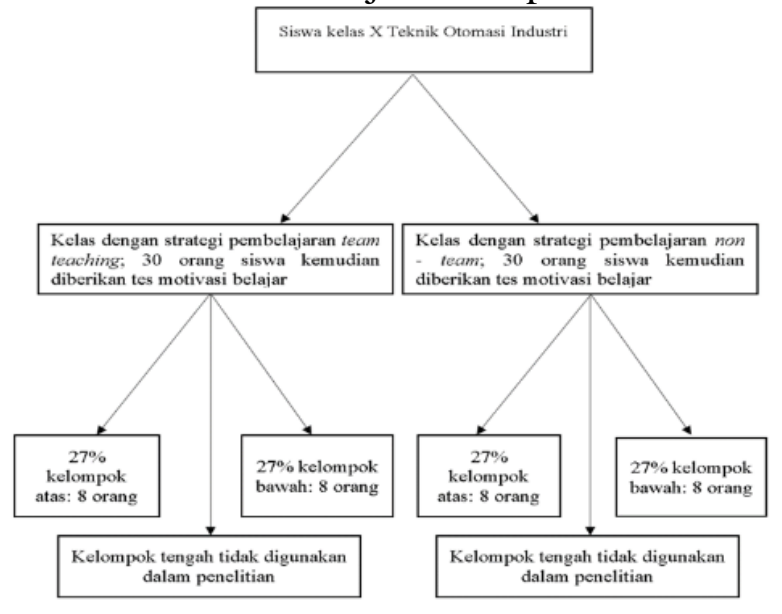

Gambar 1. Tahapan Pengambilan Sampel

\section{Instrumen Penelitian}

Penelitian ini menggunakan dua jenis instrumen yaitu; kuisioner, dan tes. Instrumen kuiseioner digunakan untuk mengukur motivasi belajar siswa terhadap mata pelajaran menganalisis rangkaian listrik. Instrumen tes digunakan untuk mengukur hasil belajar menganalisis rangkian listrik.

\section{Teknik Pengolahan Data Uji Validitas}

Untuk mengukur ketepatan data tersebut digunakan teknik uji validitas yang dihitung 
dengan rumus Korelasi Product Moment dari Pearson.

\section{Uji Reliabilitas}

Formula yang dipergunakan untuk menguji reliabilitas instrumen dalam penelitian ini adalah rumus Koefisien Alpha dari Cronbach.

\section{Teknik Analisis Data}

\section{Uji Normalitas}

Untuk menguji normalitas data, penelitian ini menggunakan uji liliefors . Adapun persamaannya adalah sebagai berikut:

Keterangan :

$$
L_{h}=\left|F_{Z I}-S_{Z I}\right|
$$

$\mathrm{L}_{\mathrm{h}} \quad$ : Liliefors hitung

$\mathrm{F}_{\mathrm{zi}} \quad$ : Probabilitas komulatif normal

$\mathrm{S}_{\mathrm{zi}} \quad$ : Probabilitas komulatif empiris

\section{Uji Homogenitas}

Uji homogenitas yang penulis gunakan adalah Uji Bartlett. Menguji hipotesis homogenitas data dengan cara membandingkan nilai $\boldsymbol{X}^{2}{ }_{\text {hitung }}$ dengan $\boldsymbol{X}^{2}$ tabel

\section{Uji Hipotesis Penelitian}

Teknik analisis data yang digunakan penulis dalam pengolahan data yaitu menggunakan Analisis Variansi (ANOVA). ANOVA ini dugunakan untuk menguji hipotesis yang berkenaan dengan perbedaan dua mean atau lebih

- Antar A (Ho : $\mu \mathrm{A} 1 \leq \mu \mathrm{A} 2 ; \mathrm{H} 1: \mu \mathrm{A} 1>\mu \mathrm{A} 2)$

- Kelompok A1B1 \& A2B1 ( Ho : $\mu \mathrm{A} 1 \mathrm{~B} 1 \leq$ $\mu \mathrm{A} 2 \mathrm{~B} 1 ; \mathrm{H} 1: \mu \mathrm{A} 1 \mathrm{~B} 1>\mu \mathrm{A} 2 \mathrm{~B} 1)$

- Kelompok A1B2 \& A2B2 (Ho : $\mu \mathrm{A} 1 \mathrm{~B} 2 \geq$ $\mu \mathrm{A} 2 \mathrm{~B} 2 ; \mathrm{H} 1: \mu \mathrm{A} 1 \mathrm{~B} 2<\mu \mathrm{A} 2 \mathrm{~B} 2)$

\section{HASIL DAN PEMBAHASAN}

1. Terdapat Perbedaan Hasil Belajar Menganalisis Rangkaian Listrik Bagi Siswa yang Mengikuti Strategi Pembelajaran Team Teaching Dan Siswa yang Mengikuti Pembelajaran dengan Strategi Pembelajaran Non-Team Teaching (A1 \& A2)

Berdasarkan hasil analisis varians dua jalan pada baris A ditemukan bahwa Fhitung lebih besar dari Ftabel (Fhitung $=49,82>$ Ftabel $(0,05 ; 1 ; 28)=4,19)$.

Hasil penelitian tersebut sejalan dengan penelitian yang dilakukan oleh Arief (2011: 70) yang berjudul pengaruh penerapan strategi pembelajaran team teaching terhadap hasil belajar siswa kelas XII SMK
Muhammadiyah Prambanan pada pembelajaran teori motor otomotif 2 dengan hasil penelitian bahwa terdapat peningkatan hasil belajar siswa kelas eksperimen sebelum mendapatkan perlakuan dengan sesudah mendapatkan perlakuan menggunakan strategi pembelajaran team teaching .

Dari hasil pembuktian tersebut di atas dapat disimpulkan bahwa pemilihan strategi pembelajaran harus disesuiakan dengan karekteristik siswa. Penggunaan strategi pembelajaran yang tepat dalam menyampaikan materi pelajaran memungkinkan siswa saling berinteraksi baik dengan guru maupun dengan siswa lainnya sehingga dapat meningkatkan hasil belajarnya.

2. Terdapat Perbedaan Bagi Siswa yang Mengikuti Strategi Pembelajaran Team Teaching Dan Memiliki Motivasi Belajar Tinggi Mempunyai Hasil Belajar yang Lebih Tinggi Dibandingkan dengan Siswa yang Mengikuti Strategi Pembelajaran Non-Team Teaching Dan Memiliki Motivasi Belajar Tinggi (A1B1 \& A2B1)

Hasil uji Dunnett pada siswa yang memiliki motivasi belajar tinggi, nilai thitung $=11,80$ lebih besar dar $\mathrm{t}$ tabel $(0,05 ; 28)=$ 1,70 .

Hasil penelitian tersebut sejalan dengan penelitian yang dilakukan oleh Mut'ah (2014: 68) yang berjudul pengaruh motivasi belajar siswa terhadap hasil belajar siswa pada bidang studi sejarah keudayaan islam di MTSN 19 Jakarta dengan hasil penelitian bahwa motivasi belajar mempunyai pengaruh yang signifikan terhadap hasil belajar siswa pada bidang studi Sejarah Kebudayaan Islam. Hal ini ditunjukkan melalui koefisien kolerasi sebesar 0,4231 .

Hal ini berarti bahwa terdapat perbedaan hasil belajar menganalisis rangkaian listrik bagi siswa yang mengikuti strategi pembelajaran team teaching dan memiliki motivasi tinggi dengan siswa yang mengikuti strategi pembelajaran non - team teaching dan memiliki motivasi tinggi.

3.Terdapat Perbedaan Bagi Siswa yang Mengikuti Strategi Pembelajaran Team Teaching Dan Memiliki Motivasi Belajar 
Rendah Mempunyai Hasil Belajar yang Lebih Rendah Dibandingkan dengan Siswa yang Mengikuti Strategi Pembelajaran NonTeam Teaching Dan Memiliki Motivasi Belajar Rendah (A1B2 \& A2B2)

Hasil uji Dunnett pada hasil belajar menganalisis rangkaian listrik dengan motivasi belajar rendah diperoleh nilai $\mathrm{t}$ hitung $=1,81$ lebih besar dari t tabel $(0,05 ; 28)$ $=1,70$. Dengan demikian dapat disimpulkan bahwa skor hasil belajar menganalisis rangkaian listrik dengan motivasi rendah, pada siswa yang mengikuti strategi pembelajaran team teaching lebih rendah daripada siswa yang mengikuti strategi pembelajaran non - team teaching.

Hasil penelitian tersebut sejalan dengan penelitian yang dilakukan oleh Chika (2014: 56) yang berjudul pengaruh metode thinktalk-write (ttw) terhadap hasil belajar geografi berdasarkan motivasi berprestasi siswa kelas $\mathrm{x}$ di SMA Kolombo Sleman Yogyakarta dengan hasil penelitian bahwa Hasil pengolahan data posttest menunjukkan mean kelas eksperimen (TTW) sebesar 14,33 dan mean kelas kontrol (konvensional) sebesar 20,58. Peningkatan nilai di kelas eksperimen adalah sebesar 0,73 . Peningkatan nilai di kelas kontrol sebesar 5,18.

Hal ini berarti bahwa terdapat perbedaan hasil belajar menganalisis rangkaian listrik bagi siswa yang mengikuti strategi pembelajaran team teaching dan memiliki motivasi belajar rendah mempunyai hasil belajar yang lebih rendah dibandingkan dengan siswa yang mengikuti strategi pembelajaran non-team teaching dan memiliki motivasi belajar rendah.

\section{KESIMPULAN DAN SARAN}

\section{Kesimpulan}

1. Hasil belajar menganalisis rangkaian listrik bagi siswa yang mengikuti strategi pembelajaran team teaching lebih tinggi dibandingkan dengan siswa yang mengikuti strategi pembelajaran non - team teaching.

2. Hasil belajar menganalisis rangkaian listrik bagi siswa yang mengikuti strategi pembelajaran team teaching dan memiliki motivasi tinggi lebih tinggi dibandingkankan dengan siswa yang mengikuti strategi pembelajaran non - team teaching dan memiliki motivasi tinggi .

3. Hasil belajar menganalisis rangkaian listrik bagi siswa yang mengikuti strategi pembelajaran team teaching dan memiliki motivasi rendah lebih rendah dibandingkankan dengan siswa yang mengikuti strategi pembelajaran non - team teaching dan memiliki motivasi rendah.

\section{Saran}

1. Guru hendaknya memilih strategi pembelajaran yang tepat sesuai dengan karakteristik siswa salah satunya dari segi motivasi belajar yang dimiliki oleh siswa agar siswa dapat meningkatkan hasil belajar sesuai dengan tujuan pembelajaran yang diharapkan.

2. Bagi siswa yang memiliki motivasi belajar tinggi sebaiknya menggunakan strategi pembelajaran team teaching, sedangkan bagi siswa yang memiliki motivasi trendah menggunakan strategi pembelajaran non team teaching.

3. Dalam penelitian ini mengungkapkan perbedaan antara strategi pembelajaran team teaching dan non-team teaching, sehingga membuka kesempatan bagi peneliti lain untuk meneliti lebih luas dan mendalam terhadap strategi pembelajaran lain yang berpengaruh terhadap hasil belajar dan motivasi belajar siswa

\section{DAFTAR PUSTAKA}

Arikunto, Suharsimi. 1984. Dasar-dasar Evaluasi Pendidikan. Jakarta: Bina Aksara

Asmani, Jamal Ma'mur. 2010. Pengembangan dan Pelaksanaan Lengkap Micro Teaching dan Team teaching. Jogjakarta: Diva Press.

Djaali. 2008. Psikologi Pendidikan. Jakarta: PT Bumi Aksara

Hutabarat, E. P. 1995. Cara Belajar: Pedoman Praktis Untuk Belajar Secara Efisien dan Aktif. Bandar Lampung

Mutmainah, Mut'ah. 2014. Pengaruh Motivasi Belajar Terhadap Hasil Belajar Siswa pada Bidang Studi Sejarah Keudayaan Islam di MTSN 19 Jakarta. Jakarta. UIN

Novriani, Chika .2014. Pengaruh Metode ThinkTalk-Write (TTW) Terhadap Hasil Belajar 
Geografi Berdasarkan Motivasi Berprestasi Siswa Kelas X Di SMA Kolombo Sleman Yogyakarta. Yogyakarta. UNY

Roestiyah N K. 1982. Masalah-masalah Ilmu Keguruan. Jakarta: Bina Aksara

Siregar, Eveline dan Nara, Hartini. 2007. Buku Ajar Teori Belajar dan Pembelajaran. Jakarta: FIP Universitas Negeri Jakarta

Sudjana, Nana. 2001. Penilaian Hasil Proses Belajar Mengajar. Bandung: PT Remaja Rosdakarya

Sutopo, Arief Hari. 2011. Pengaruh Penerapan Strategi Pembelajaran 